of aldehydes with ketones to give the piperonyl insecticides, and under the Felt Fellowship notable progress has been made in the evaluation of cloth filters and the mechanical napping of fabrics. Under the Fellowship on Match Technology researches have begun on improving the resistance of matches to water and high humidity, the selection of binders, etc. During the tenure of the Fellowship on Organic Synthesis new reactions of diketen with the sodium derivatives of pentadione and acetoacetic esters have been discovered, a study of the effects of chemicals on cellulosic and synthetic fibres has been inaugurated and a series of non-ionic surface agents elaborated, the functionality of which in aqueous solution is not greatly affected by temperature, concentration or the presence of polyvalent metal ions and neutral electrolytes ; also real progress has been made in 'Vinylite' resin organosol decorative metal finishes. The development of the 'Stypol' resins, a series of liquid thermosetting materials, has continued under the Protected Metals Fellowship, while work of that on Protective Coatings has placed its main emphasis on the development of coatings for military use and the replacement of scarce materials. Two new types of floor coverings, 'Accotred' and 'Vinoflor', were developed under the Cork Fellowship, and research on synthetic paint-brush bristle was a feature of the work of the Special Fibres Fellowship.

\section{PREPARATION AND PUBLICATION OF SCIENTIFIC PAPERS}

$I^{T}$

$\mathrm{T}$ is sometimes customary for scientific societies to give advice and guidance to intending authors as to the preparation of their articles in a form suitable for inclusion in the societies' journals. Usually the advice is limited to some warning about the best method of writing mathematical expressions or to the peculiar layout or spelling adopted by the journal.

A much more comprehensive and instructive manual for intending authors is the revised edition of the booklet "Notes on the Preparation of Contributions to the Institute's Journals and Other Publications" recently issued by the Institute of Physics. The "Notes" were first published in 1931 and were last revised in 1950. No fundamental changes have been made in the new edition; but the opportunity has been taken to make minor corrections and some alterations in acceptable spellings and abbreviations in conformity with recent international and other agreements. Information is given concerning the Institute's publications, the types of contributions acceptable and the conditions of acceptance. Though it is obviously advisable in order to avoid delay in appearance for contributions to conform rigidly with the usages set out in the "Notes", this is not a condition of acceptance.

The "Notes" deal in detail with the preparation, length and cost of text, the form of script and diagrams, the presentation of tabular matter and mathematical expressions and the correction of proofs. Four pages of the booklet are devoted to the proper presentation of circuit, mainly electronic, elements; this seems excessive when it is considered that the Institute's journals do not cater for purely electronic subjects. An interesting reference is to the present average total cost, $\mathfrak{f 1 0}$, of each page of text of a line figure $£ 2$ or half-tone $£ 210 s$.; of a typical minor change to a line of type once it is set $5 s$. , or of removing a comma $1 s .6 d$. This should act as sufficient warning to authors to be extremely careful, to be concise, to avoid unnecessary diagrams and figures and, above all, to revise their manuscripts before submission for publication.

A short bibliography of dictionaries and books on writing scientific and non-technical literature is included in the "Notes", and the detailed appendixes, containing notes and examples of spellings, symbols and abbreviations, the Greek alphabet in Greek and with English equivalents, and printers' marks for correcting proofs, should prove most useful and save authors much valuable time. It is a pity that in what is otherwise an excellent manual there are still a few misprints and that the graphical diagram given on p. 13 to indicate the usual faults made by authors is by no means a clear and good example. S. WeINTROUB

\section{DETERMINATION OF PROTEIN CRYSTAL DENSITIES}

$$
\text { BY DR. BARBARA W. LOW }
$$

FREDERIC M. RICHARDS

University Laboratory of Physical Chemistry related to Medicine and Public Health, Harvard University, 25 Shattuck Street, Boston, Mass.

$T$ HE accurate measurement of protein crystal densities under a variety of conditions is important for the determination of protein molecular weights by the X-ray diffraction method, and for the study of the composition of these crystals. In order to make best use of the results, it is essential that all the measurements be made on crystals of precisely the same composition. Protein crystals equilibrate rapidly by the loss or gain of water, or by the pene-

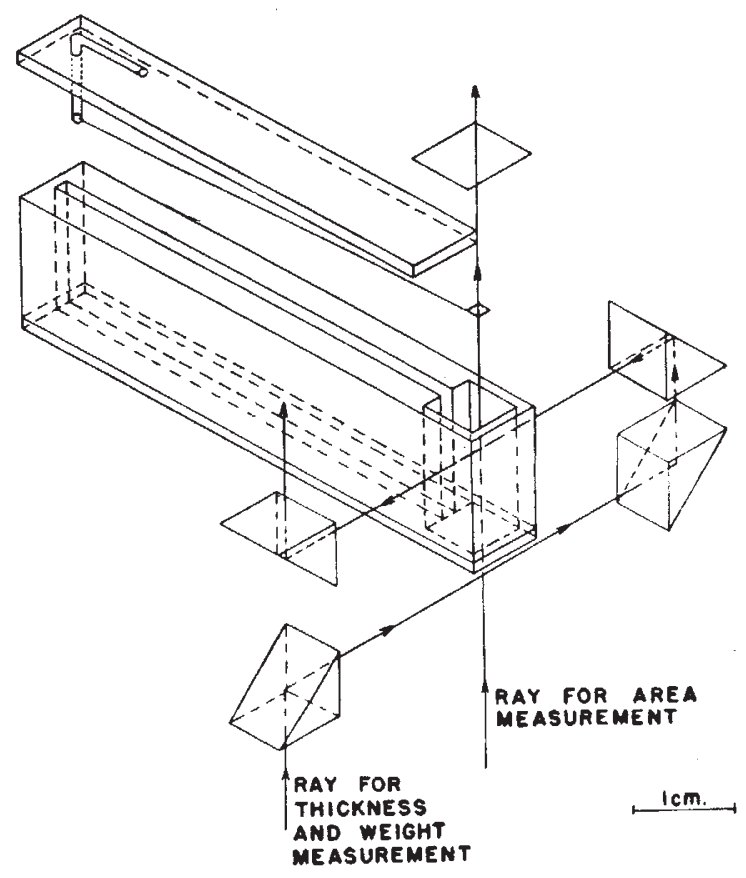

Fig. 1. Schematic diagram of microbalance assembly 